\title{
LEVINAS Y LA ALTERIDAD: CINCO PLANOS
}

\author{
Olaya Fernández Guerrero \\ Universidad de La Rioja
}

RESUMEN: Este trabajo revisa las concepciones de la alteridad desarrolladas por Levinas, y muestra cinco planos fundamentales en torno a los que este filósofo plantea esta noción. Se trata de las dimensiones metafísica, religiosa, subjetiva, lingüística y ética, todas ellas estrechamente conectadas entre sí y que ofrecen múltiples perspectivas para reflexionar sobre la alteridad.

Palabras clave: Alteridad, ética, Levinas, metafísica, rostro.

\section{LEVINAS AND ALTERITY: FIVE LAYERS}

ABSTRACT: This paper reviews the concept of alterity developed by Levinas, and it shows five fundamental areas around which this philosopher raises this issue. These are the metaphysical, religious, subjective, linguistic and ethical dimensions, all of them closely interconnected. They provide multiple perspectives to reflect on alterity.

Keywords: Alterity, Ethics, face, Levinas, Metaphysics.

\section{Introducción: alter y ego}

La filosofía de la alteridad es una de las aportaciones más novedosas del panorama contemporáneo, y que permite abordar la diferencia en toda su complejidad. Alter es un pronombre latino formado a partir del sustantivo alius -otro, distinto, diferente-, al que se añade el sufijo -ter, que diferencia a un elemento de otro dentro de un par. Así, alter se contrapone a ego, lo otro a lo mismo, pero ambas categorías se definen de modo relacional, remiten la una a la otra hasta el punto de que la identidad individual no se concibe sin incluir en esa definición 
la dimensión de alteridad, otredad o diferencia, con la que cada individualidad se relaciona. El pensamiento de la alteridad pone el acento en esta perspectiva relacional y abierta de la subjetividad, y reflexiona sobre las dimensiones y posibilidades que se derivan de ahí. La hipótesis de partida es que la identidad no es algo que pueda fundamentarse en presupuestos solipsistas, sino que para dar cuenta de ella de forma adecuada es imprescindible tomar en consideración la exterioridad y los variados modos de relación con ella. La filosofía de la alteridad busca superar la separación radical entre sujeto y objeto promovida por el racionalismo de cuño cartesiano, y repensar los límites entre el yo que piensa y el contenido de lo que es pensado, mostrando que esos límites no son tan claros como pudiese parecer a priori, y que más bien hay una cierta continuidad entre el sujeto y el mundo, entre el yo y el contexto vital en que está situado. A partir de estas ideas, tomadas principalmente de Husserl y Heidegger, el filósofo lituano Emmanuel Levinas ha desplegado un amplio marco conceptual que aborda la alteridad en toda su complejidad y que desentraña los distintos planos asociados a esta noción. De esos planos nos ocuparemos en este trabajo.

\section{Los cinco planos de la alteridad}

A partir de una lectura atenta de la obra de Levinas, pueden destacarse cinco niveles o aspectos de la alteridad que, si bien aquí serán desglosados y expuestos de forma analítica, aparecen estrechamente interconectados en los planteamientos del autor.

- Plano metafísico: En primer lugar, la idea de alteridad surge de la constatación de que existe una otredad radical, no asimilable a la lógica de lo Uno y de lo Mismo que ha predominado en la tradición metafísica occidental, según la crítica que desarrolla Levinas. Más allá de la identidad, hay una lógica de la alteridad que posibilita una comprensión del ser -y, por ende, de la ontología- mucho más adecuada que la que se deriva de la lógica de la identidad.

- Plano religioso: En una de sus vertientes más radicales, la alteridad se manifiesta como infinitud, como totalidad cuyos límites resultan inaprehensibles y que, no obstante, aspiramos a alcanzar. Ese deseo de infinitud lo relaciona Levinas con la dimensión religiosa, con la búsqueda de lo absoluto que caracteriza a la persona de fe. El autor, de origen judío, conecta además la idea de infinitud con la idea de Dios.

- Plano individual: En otro nivel, se asume que la alteridad forma parte de la propia identidad, en tanto que aquello que nos particulariza y describe como individuos, lo que denominamos personalidad o carácter, es precisamente una suma de acontecimientos heterogéneos, una síntesis de todos los momentos vividos y experimentados de forma concreta, única e intransferible. 
- Plano intersubjetivo: a través del lenguaje nos abrimos a la alteridad, la palabra siempre es una interpelación que el otro me lanza y a la que yo respondo o, al menos, tengo el imperativo ético de responder -ambas dimensiones, la ética y la lingüística, están estrechamente conectadas en los planteamientos de Levinas-. Esa respuesta supone, ya desde el comienzo, un intento de comprender su alteridad, de acercarme a ella sin anularla. En todo caso, la dimensión comunicativa es fundamental para este filósofo.

- Plano ético: capto al otro como alteridad que no poseo ni puedo poseer, y esto me induce a respetar al otro en su diferencia y especificidad. La ética aflora, pues, de la confrontación directa con el rostro del otro y la actitud receptiva frente a la interpelación directa que ese rostro me lanza. En el plano ético confluyen todos los demás, ya que a través de la toma de conciencia de la alteridad del otro, y de mi propia alteridad constitutiva, comienza un nuevo proyecto de relación interpersonal basado en el diálogo, el respeto, la tolerancia, y la aceptación de la diferencia -y no solo de la semejanza-.

\section{La alteridad en sentido metafísico: más allá de lo Uno}

A lo largo de toda su obra, pero particularmente en Totalidad e infinito, Levinas perfila una noción de alteridad como dimensión originaria previa a todo conocimiento, anterior a todo intento de conceptualización o aprehensión de la realidad desde una perspectiva humana. Siguiendo a Heidegger y Husserl, indaga en las raíces de la ontología y descubre que más allá de ella aflora un plano metafísico que se desvela como alteridad radical, que no se deja apresar y que no es asimilable a nada conocido o cognoscible, sino que antecede a todo y funciona como condición de posibilidad de todo: "Lo Otro metafísico es [...] una alteridad que no es un simple revés de la identidad, ni de una alteridad hecha de resistencia al Mismo, sino como una alteridad anterior a toda iniciativa, a todo imperialismo del Mismo"1. La realidad es heterogénea, múltiple e inabarcable, y todo ello viene expresado para Levinas por esa noción de alteridad que apunta hacia esos rasgos esenciales de la mundaneidad que preceden a todo acto, a toda tarea de dar sentido y comprender el mundo.

El pensador lituano considera que la filosofía occidental desde Sócrates en adelante ha dado preponderancia a las lógicas de la identidad, y esto ha desembocado en una visión incompleta del ser que es incapaz de dar cuenta de su multiplicidad. La filosofía ha supuesto "una reducción de lo Otro al Mismo", ${ }^{2}$ y la consecuencia de esta aproximación ha sido que todo conocimiento se ha explicado en términos de comprehensión, ha pretendido abarcar el ser homogenei-

1. Levinas, E., Totalidad e infinito. Ensayo sobre la exterioridad. Salamanca, Sígueme, 1999, p. 62.

2. Levinas, E., Totalidad e infinito, p. 67. 
zándolo: "Conocer viene a ser aprehender el ser a partir de nada o Ilevarlo a la nada, quitarle su alteridad". ${ }^{3}$ Desde Parménides hasta Heidegger, el pensamiento ha estado dominado por la 'primacía del Mismo' que ha cancelado la posibilidad de que emerja la diferencia. El problema, sostiene Levinas, estriba en que esa denodada búsqueda de la unidad y la identidad "no respeta la alteridad del otro"4 sino que la subsume y somete al criterio de lo Uno, considerado ontológicamente superior. Así, esa dimensión de alteridad que está presente de modo primigenio y que para este filósofo se sitúa en un plano metafísico, acaba siendo desplazada por un pensamiento filosófico centrado en la ontología y articulado en torno al concepto de unidad ${ }^{5}$. En esa perspectiva prevalece el deseo de apropiación, asimilación de lo Otro y subsunción bajo categorías unitarias; Levinas es claro al respecto: "la posesión es la forma por excelencia bajo la cual el Otro llega a ser el Mismo llegando a ser mío"6, y el resultado de ese proceso de apropiación es la pérdida de la diferencia, la negación de la alteridad que sucumbe bajo el peso de la búsqueda de lo común e identitario. "El saber presupone el yo. Todo saber del aquí es ya un saber para mí que estoy aquí. El saber se funda en la mismidad"7.

Más allá de ese modelo de pensamiento enfocado hacia la identidad e unidad, que privilegia la semejanza y anula la alteridad primordial de lo radicalmente otro, Levinas se decanta por un paradigma alternativo que consiste en "pensar lo infinito, lo trascendente ${ }^{\prime \prime}$, que trasciende toda identidad pero que a la vez es su condición de posibilidad, ya que en cada aproximación a la comprensión, en cada búsqueda de sentido, está latente un deseo de captar esa alteridad, parcelarla y encerrarla en conceptos fijos. Su pensamiento se perfila como un esfuerzo por definir, a partir de la alteridad, "la relación entre el Uno y los muchos, sin tener que recurrir a un término neutro que haga que los opuestos entren de nuevo en una totalidad" ${ }^{\prime \prime}$, pues en la idea de totalidad ya está implícito un retorno a lo unitario que nuestro filósofo quiere evitar a toda costa. En estas consideraciones subyace una concepción dual originaria, una contraposición de carácter dialéctico en la que, sin embargo, no hay superación ni integración sintética de las dos dimensiones contrapuestas, como sí

3. Levinas, E., Totalidad e infinito, p. 68. Levinas identifica el origen de este modelo de conocimiento en la mayéutica socrática, que instaura la 'primacía del Mismo' al asumir que en el aprendizaje no se recibe nada del Otro, sino que únicamente se saca 'a la luz' lo que ya está previamente dado en el individuo.

4. Reyes Pedraza, J., "La alteridad en Emmanuel Levinas", Martínez Contreras y Ponce de León (coords.). El saber filosófico. Sociedad y ciencia. México, Siglo XXI, 2007, pp. 159-167, p. 161.

5. Recordemos que para los filósofos presocráticos e incluso para Platón o Aristóteles uno de los principales objetivos era hallar lo unitario, el principio básico que subyace a la multiplicidad y que conecta entre sí todas las cosas, que es lo común a todos los entes.

6. Levinas, E., Totalidad e infinito, p. 70.

7. Levinas, E., “¿Es fundamental la ontología?", Entre nosotros. Ensayos para pensar en otro. Valencia, Pre-textos, 2001, p. 40.

8. Levinas, E., Totalidad e infinito, p. 73.

9. Samoná, L., Diferencia y alteridad. Después del estructuralismo: Derrida y Levinas. Madrid, Akal, 2005, p. 55. 
acontece en el modelo hegeliano. Levinas asume que la dualidad entre lo Mismo y lo Otro no se resuelve nunca, la brecha que separa ambas dimensiones es insalvable y por ello pensar la totalidad, el infinito, la alteridad, implica llevar el pensamiento hasta el límite para, a partir de ahí, intentar sondear lo insondable, lo ilimitado, que por definición resulta inasequible al pensamiento.

Para reformular la alteridad como lo radicalmente Otro y preservar su especificidad frente a todas las categorías de unidad e identidad que amenazan con neutralizarla, este autor recurre a la idea de infinito, que engloba aquello que "permanece siempre exterior al pensamiento", por cuanto "el infinito desborda el pensamiento que lo piensa"..$^{10}$ Esta noción de infinitud proporciona el fundamento para apuntalar una definición de alteridad entendida como 'heterogeneidad radical de lo Otro', que "sólo es posible si lo Otro es otro con relación a un término cuya esencia es permanecer en el punto de partida, servir de entrada a la relación, ser el Mismo no relativamente, sino absolutamente".$^{11}$ Lo Otro está más allá de los límites de lo Mismo, su inconmensurabilidad es de carácter metafísico y antecede a todo relato ontológico.

Levinas atribuye a la alteridad una esencia que consiste precisamente en ser exterioridad absoluta de lo Otro con respecto al Mismo, y que motiva que lo Otro se nos presente siempre como inagotable e inabarcable en su totalidad - de ahí la noción de infinito, que alude a esa carencia de límites-. De acuerdo con este planteamiento "la alteridad se significa en el darse lo Infinito al Mismo",12 pero sin perder de vista que ambas categorías son esencialmente diferentes y que el encuentro a través de ese 'darse' surge siempre desde una postura inicial de separación radical. En la metafísica del Otro, "el Yo es destituido de su posición dominante de sujeto trascendental"13 y pasa a definirse como un ser relacional, que se posiciona con respecto a la alteridad y que precisamente se erige en sujeto cuando se confronta a otro sujeto diferente, a una otredad que le interpela. En ese intersticio es donde aflora la dimensión ética, a la que nos referiremos luego.

\section{Alteridad como infinito y aparición del horizonte religioso}

Levinas profundiza en la noción de infinito y plantea que la única forma legítima de acercarnos a esa dimensión es a través de la aproximación, pero sabiendo que la alteridad que el infinito representa trasciende el entendimiento humano y,

10. Levinas, E., Totalidad e infinito, p. 51.

11. Levinas, E., Totalidad e infinito, p. 60.

12. Quesada Talavera, B., "Aproximación al concepto de 'alteridad' en Lévinas. Propedéutica de una nueva ética como filosofía primera". Investigaciones fenomenológicas, 3 (2011), pp. 393-405, p. 394.

13. Pérez Quintana, A., "La crítica de Levinas a la filosofía trascendental moderna", Alonso Martos. Emmanuel Lévinas. La filosofía como ética. Valencia, Universitat de València, 2008, pp. 69-90, p. 78. 
desde luego, no se deja captar como totalidad. "La relación con lo Infinito no es conocimiento sino proximidad que preserva la desmesura de lo que no puede ser englobado y que aflora"14, y aceptar esto equivale a asumir a priori la imposibilidad de apropiarnos de lo Otro y acabar subsumiéndolo en lo Mismo, y desechar definitivamente esa pretensión.

Precisamente en esa relación deseante que el ser humano mantiene con la alteridad, concebida aquí como algo que anhela pero que no puede aprehender por completo, es donde surge para Levinas la idea de Dios, el sentimiento religioso. "La idea de Dios es a la vez Dios mismo, pero en la separación"15, y para este filósofo la alternancia entre esa presencia y ausencia de la divinidad es lo que está en la base de la fe, y asimismo abre al individuo a un nuevo modo de relacionarse con la alteridad constituyente del cosmos. Se trata de pensar lo infinito, de pensar a Dios no solo como un consuelo de la finitud o una satisfacción del 'hambre de eternidad' a la que ya se refirió Unamuno, sino de ir más allá y explorar las posibilidades que ese concepto representa. Levinas insiste en el valor de la originalidad irreductible de la alteridad y de la trascendencia, que no se deja aprehender adecuadamente si la reducimos a "una interpretación puramente negativa de la proximidad ética y del amor"16, ya que la energía espiritual no se agota en esa articulación negativa sino que tiene mucho más recorrido, mucha más apertura, mucha más Otredad radical de la que podemos llegar a captar por la vía del conocimiento, que para él siempre conlleva una cierta violencia, dominación, y subsunción de lo otro en lo mismo. En el plano religioso, "la alteridad tiene el carácter de lo divino que se presenta en la irreductibilidad de aquello que es exterior o interior a la comunidad del concepto"17, remite a lo inefable y trascendente que no se deja etiquetar en categorías o nociones fijas, tal es la idea de Dios que, según el discurso teológico, solo puede conocerse por aproximación, y en cualquier caso de modo incompleto dado que la mente finita no puede hacer inteligible lo infinito. ${ }^{18}$

14. Levinas, E., "¿Un Dios hombre?", Entre nosotros, p. 75.

15. Samoná, L., Diferencia y alteridad, p. 57.

16. Levinas, E., "Sobre la idea de infinito en nosotros", Entre nosotros, p. 262.

17. Samoná, L., Diferencia y alteridad, p. 82.

18. Sobre esta cuestión puede recordarse el relato medieval, no se sabe si real o inventado, que cuenta que San Agustín de Hipona paseaba un día por la playa mientras iba reflexionando sobre el misterio de la Santísima Trinidad. En su paseo, encontró a un niño que había excavado un pequeño hoyo en la arena y trataba de llenarlo con agua del mar. El niño corría hacia el mar, recogía agua en una concha marina y la vertía en el hueco, una y otra vez. Cuando el santo le preguntó qué hacía, el niño le respondió que intentaba meter toda el agua del océano en el hoyo. San Agustín le dijo que aquello era imposible, y el niño le contestó que era tan imposible meter toda el agua del océano en el hoyo como pretender comprender, con una mente finita, el misterio de Dios que es infinito. El mismo tipo de argumento está presente en Descartes cuando afirma que, dado que los seres finitos no podemos captar lo infinito, y sin embargo tenemos en nuestro intelecto la idea de infinitud, esa idea solamente puede ser de tipo innato y ha de provenir de un ser infinito que la ha puesto en el ser humano. Ese ser se identifica con Dios, y así queda justificada su existencia, según el filósofo francés. 
La noción de Dios, entendida en estos términos, actúa como una alteridad fundante de la que surgen todas las demás alteridades; Levinas lo explica de modo inductivo, arrancando de lo particular, al plantear que "la emergencia de lo humano ha sido posibilitada por el otro hombre"19, y que esa relación ética establecida entre dos seres humanos concretos se hace posible "gracias a alguien 'de otro modo que ser': el Otro-distinto que se expresa, que configura al ser mismo como exterioridad [...], como presencia de Dios"20. Así pues, la alteridad de lo infinito y trascendente, identificada ahora con lo divino, funciona como fundamento ontológico de todos los demás niveles de alteridad a los que los seres humanos tenemos acceso y que, asimismo, son constitutivos de nuestro mundo. Dios simboliza lo inefable, aquello que no se deja abarcar por la palabra o por el concepto sino que se sitúa más allá de los confines de la racionalidad, y cuya alteridad es inasequible al pensamiento humano ${ }^{21}$. En síntesis, Dios refleja la trascendencia de modo paradigmático: "La fina voz silenciosa de la que habla la Biblia, esta idea de una verdad perseguida, ¿no es acaso la única modalidad posible de la trascendencia?"22. Nuestra condición de seres finitos limita el alcance de nuestras posibilidades de captar la trascendencia, y el único acceso a la misma se produce por aproximación, por un deseo y tendencia hacia lo trascendente que, para Levinas, se identifica con el sentimiento religioso. Ahora bien, este autor advierte que la relación con la trascendencia se resuelve de formas diferentes en la religión y en la filosofía ya que, mientras la religión promueve un horizonte de salvación que supera la separación originaria y la resuelve mediante la conexión (re-ligación) entre el ser humano y Dios, anulando así la distancia que separa a ambos, la filosofía no busca cancelar esa brecha sino que la salvaguarda, "persevera en esa separación"23, y el propio Levinas lidera esa postura filosófica que afirma a la vez el sujeto y la trascendencia, pero que renuncia a todo intento de cancelar la distancia entre ambas dimensiones.

\section{Identidad individual y alteridad}

"Ser yo es [...] tener la identidad como contenido. El yo no es un ser que permanece siempre el mismo, sino el ser cuyo existir consiste en identificarse, en recuperar su identidad a través de todo lo que le acontece ${ }^{\prime 24}$. Aquello que denominamos 'identidad', y que aparentemente se asocia a la solidez y cohesión

19. Samoná, L., Diferencia y alteridad, p. 76.

20. Samoná, L., Diferencia y alteridad, p. 76. En cierto modo, el recorrido que hace Levinas para plantear esta cuestión guarda paralelismos con la argumentación cartesiana citada arriba.

21. En el contexto cristiano, nociones teológicas como los 'misterios de Dios' aluden a esta insondabilidad, a esta incapacidad de entender los designios divinos.

22. Levinas, E., "¿Un Dios hombre?", Entre nosotros, p. 73.

23. Samoná, L., Diferencia y alteridad, p. 57.

24. Levinas, E., Totalidad e infinito, p. 60. 
que nos hace 'ser el que se es', no es más que el resultado de una sucesión de heterogeneidades con las que el individuo se ve obligado a enfrentarse y rehacerse constantemente ${ }^{25}$. En definitiva, lo que individualiza y particulariza a cada sujeto es el conjunto finito de acciones que ese sujeto hace y padece en su contexto mundano; tomar en cuenta esa interacción con el entorno no permite ya concebir la identidad individual en términos estáticos, fijos, inamovibles, sino que abre la puerta a la consideración de la identidad como un resultado parcial de un proceso dinámico que nunca se detiene, que es puro devenir. Siguiendo los postulados de la fenomenología de Husserl, Levinas reitera que para hablar de identidad es imprescindible "partir de la relación concreta entre un yo y un mundo" 26 , ya que es ahí donde emerge la subjetividad, donde el Yo se revela como el Mismo a través de todos los acontecimientos que constituyen su entorno vital.

El individuo no es una entidad cerrada, no es una "mónada sin ventanas" al estilo leibniziano sino que, ineludiblemente, existe en situación, adviene al mundo y se despliega en el mundo. El yo sale de sí porque es, constitutivamente, un ser dotado de conciencia y de intencionalidad, volcado hacia el mundo -en este sentido, Levinas es fiel a los planteamientos de Heidegger y Husserl-. La estructura intencional de la conciencia nos mantiene en constante "estado de yecto" -en la terminología de Heidegger-, de apertura hacia el mundo, lo que posibilita todo conocimiento -porque la conciencia siempre es conciencia de algo, como dirá Husserl-, y además esa misma conciencia es capaz de volverse sobre sí misma, de desplegar un movimiento auto-reflexivo: el sujeto se toma a sí mismo como objeto de reflexión, y aparece entonces la noción de identidad. Pero Levinas da un paso más con respecto a Husserl, cuyo planteamiento sobre la intencionalidad de la conciencia está todavía anclado en una posición que da primacía al sujeto, del que parte toda iniciativa de conocimiento y aproximación al mundo de la vida que lo rodea. Para el filósofo lituano, por el contrario, "la subjetividad del sujeto se descentra y se destituye ${ }^{\prime 27}$ para ser reexaminada a la luz de la alteridad; es el Otro que viene hacia mí e interactúa conmigo lo que hace emerger mi identidad individual, y no al revés. La exterioridad es previa a la constitución de la identidad, hasta el punto de que "el otro interviene en las mismas nociones de ser y de sujeto" ${ }^{\prime 28}$. Se establece aquí la preminencia ontológica de la alteridad sobre la identidad, dando un vuelco a toda la metafísica occidental que ha planteado esta cuestión a la inversa.

25. Desde esta lectura, el equilibrio de la identidad se parecería más a los estados de equilibrio descritos por las leyes de la termodinámica, que afirman que, dado un sistema cualquiera, ese sistema tenderá a evolucionar de un estado de equilibrio a otro para adaptarse de forma más flexible a sus propios contornos y las restricciones a las que esos contornos estén sometidos.

26. Levinas, E., Totalidad e infinito, p. 61.

27. Bensussan, G., "Intransitividad de la ética", Alonso Martos. Emmanuel Lévinas..., pp. 29-40, p. 33.

28. Samoná, L., Diferencia y alteridad, p. 54. 
En el sujeto confluyen y se entrelazan la apertura a la exterioridad y el repliegue sobre sí, el deseo de infinitud y la consciencia de ser finito, y esta dualidad está en la base de todo proceso de articulación de identidades individuales. Se postula entonces que "la identidad tiene el carácter reflexivo de la inclusión de lo heterogéneo ${ }^{\prime 29}$, emerge como el resultado de un intento de entresacar, de entre todos los instantes y acontecimientos que conforman una existencia concreta, aquellos aspectos o notas definitorias que parecen más relevantes, y que se insertan en un relato más o menos coherente, en una narración verosímil en la que el sujeto da cuenta de sí mismo ante otro. La identidad del sujeto está siempre enredada en esa alternancia entre exterioridad e interioridad. De ahí se sigue que la alteridad se manifiesta a nivel interno, "en el interior de la economía de la reflexión, haciendo imposible una clausura total". ${ }^{30}$ Pero, como ya se ha expuesto más arriba, esa identidad no queda recluida en la interioridad del sujeto sino que vuelve una y otra vez a plasmarse como exterioridad, en tanto que el yo que habla de sí lo hace frente a otro que no es yo, profiere un relato sobre sí que se expone a la mirada del otro, que se representa ante el rostro del otro. "El mundo sensible sólo se torna un mundo personal y orientado cuando yo, el Mismo, represento para el Otro lo que está presente allí"131. En definitiva, es la confrontación con la alteridad lo que da sentido a cualquier elaboración discursiva sobre la identidad, porque esa elaboración discursiva -y aquí entra en juego la dimensión lingüística, que luego será analizada con más detenimiento- siempre es un acto comunicativo que requiere, al menos, un hablante y un oyente, un emisor y un receptor, un yo y un tú. La dimensión intersubjetiva, entonces, está implícita en todos los procesos de construcción de la identidad, en tanto que esa identidad solo se percibe como tal por otro que está frente a uno, o, en el caso de la auto-percepción de la identidad, cuando el yo se toma a sí mismo como otro, como una cosa que puede ser conocida y re-conocida en virtud de la capacidad de autorreflexión.

Recapitulando, puede afirmarse que para Levinas la identidad individual se articula a partir de la relación con la alteridad, al menos, en tres momentos distintos. Primero, cuando el individuo constitutivamente abierto al mundo interactúa con él. Esto implica una relación con la alteridad en tanto que exterioridad. Segundo, cuando el individuo reflexiona sobre su propia relación con el mundo y entresaca a partir de ahí un relato sintético acerca de su identidad, que es en verdad un relato sobre su modo particular de desenvolverse en la existencia y

29. Samoná, L., Diferencia y alteridad, p. 64.

30. Samoná, L., Diferencia y alteridad, p. 73. Como ya señaló Husserl, a través de la reducción fenomenológica la conciencia logra captarse a sí misma como conciencia intencional, esa apertura hacia el mundo es constitutiva de la conciencia y resulta ineludible, por ello la clausura total es imposible y el sujeto siempre está volcado hacia esa alteridad que le rodea y que forma parte de su 'mundo de la vida'.

31. Llewelyn, J., Emmanuel Levinas. La genealogía de la ética. Madrid, Encuentro, 1999, p. 143. 
de imbricarse en su contexto vital. Esto supone vérselas con la alteridad dentro de sí. Tercero, cuando el individuo profiere ese relato ante otro distinto a sí, esto es, se presenta y comparece ante la alteridad. Esta última vertiente alude a la confrontación entre una identidad y una alteridad concretas, incardinadas en un yo y un otro, en un yo que se sitúa frente al rostro del otro y que se relaciona con él a través del lenguaje.

\section{Lenguaje y apertura hacia la alteridad}

La dimensión lingüística ocupa un papel central en la explicación de Levinas acerca de los modos de relación con la alteridad, hasta el punto de considerar que, en el ser humano, la apertura a esa relación viene posibilitada por el lenguaje. Ello se debe a que el lenguaje siempre está referido a la alteridad, volcado hacia ella: "el discurso es [...] el vínculo que no puede quedar recluido plenamente en el enunciado, porque reivindica ya desde siempre al Otro-distinto, porque habla al Otro-distinto" ${ }^{\prime 32}$. Para que exista lenguaje tiene que haber un yo y un tú que intercambian palabras, que se hablan recíprocamente, ya que la esencia del lenguaje es "la interpelación, el vocativo". ${ }^{33}$ La palabra "se coloca ya en el interior del cara-a-cara original del lenguaje" 34 , siempre requiere que haya, como mínimo, alguien que la profiere y alguien que la recibe, implica una pluralidad originaria y permite poner en común esa pluralidad sin llegar a simplificarla ni reducir o anular la alteridad del otro a la que el discurso se dirige.

El lenguaje siempre es "un ir al encuentro de la expresión del Otro-distinto, acogiéndola"35, la escucha es un proceso activo que acoge la diferencia y que la deja ser en toda su amplitud sin intentar delimitarla ni coartarla, que la deja expresarse en tanto que alteridad. La presencia real del otro "se cumple en la audición, toma su sentido de ese papel de origen trascendente que juega la palabra proferida" ${ }^{\prime 36}$. La palabra tiende un puente entre dos alteridades, y en este sentido afirma Levinas que el lenguaje implica siempre una conexión de lo heterogéneo: "hablar es volver el mundo común"37, es buscar la koiné que permite a los sujetos devenir recíprocamente inteligibles, al menos en parte. El lenguaje "despierta en mí y en los otros lo que tenemos en común. Pero supone, en su intención expresiva, nuestra alteridad y nuestra dualidad" ${ }^{\prime 38}$, porque siempre hay yo y otro, dos sujetos distintos que se posicionan como tales uno frente a otro $y$

32. Samoná, L., Diferencia y alteridad, p. 77.

33. Levinas, E., Totalidad e infinito, p. 92.

34. Levinas, E., Totalidad e infinito, p. 220.

35. Samoná, L., Diferencia y alteridad, p. 77.

36. Levinas, E., "La presencia de las palabras. A propósito de 'biffures'", Fuera del sujeto. Madrid, Caparrós, 1997, p. 161.

37. Levinas, E., Totalidad e infinito, p. 99.

38. Levinas, E., “¿Es fundamental la ontología?", Entre nosotros, p. 39. 
que, no obstante, son capaces de encontrarse y reconocerse mutuamente como alteridad porque hablan entre sí, porque interactúan comunicándose. "El 'Decir' es una aproximación al prójimo"39, y el lenguaje está ya implícito en la relación que se entabla con el otro en la medida en que "el otro no es primero objeto de comprensión y después interlocutor. Las dos relaciones se confunden [...]. La invocación del otro es inseparable de su comprensión" ${ }^{\prime \prime 40}$. El único nivel del lenguaje que permite esa posibilidad de encuentro con la alteridad es, para Levinas, el diálogo entre dos co-existentes, hasta el punto de que "la experiencia indispensable es la de responder a otra persona" ${ }^{\prime \prime 1}$. El otro me interpela directamente, me interroga, y al hacerlo me insta a salir de mi mismidad o ensimismamiento y responder a esa llamada que me hace a mí, situado frente a mí. Levinas habla aquí de 'solicitud', un término tomado de Heidegger que alude a la disponibilidad para atender la Ilamada del otro. "El sujeto que habla no sitúa el mundo el relación consigo mismo [...] sino en relación con el otro" ${ }^{\prime \prime 2}$, expresarse es desplazar el centro de gravedad del conocimiento hacia un lugar que está fuera del individuo, es volcarse hacia la exterioridad.

Entendida en estos términos, la palabra hablada es superior a la escrita, a la que Levinas considera letra muerta incapaz de generar ningún tipo de movimiento o apertura hacia lo Otro ${ }^{43}$. "El discurso impersonal es un discurso necrológico. El hombre se reduce al legado del hombre, es absorbido por una totalidad de patrimonio común" ${ }^{\prime 4}$, y el ejemplo paradigmático de ello es el texto histórico, que presenta el tiempo presente como el resultado irrevocable de la sucesión de acontecimientos del pasado. Frente a esto, se afirma que "solo en el discurso entre seres singulares se constituye la significación interindividual de los seres y las cosas, es decir, la universalidad"45. Lo universal se alcanza a través del diálogo, y aquí es evidente la cercanía de Levinas con los postulados de Habermas y Apel, cuyo modelo ético sitúa la racionalidad comunicativa en la base de todo intento de llegar a consensos y acuerdos legítimos acerca de las normas morales que deben regir la vida en común. Para Levinas, el lenguaje y el diálogo suponen una alternativa a la violencia, puesto que responder al otro que habla, reconocer su alteridad, conlleva aceptar que el otro es distinto a mí y que, sin embargo, podemos

39. Levinas, E., 'Los derechos humanos y los derechos del otro', Fuera del sujeto, p. 156.

40. Levinas, E., "¿Es fundamental la ontología?", Entre nosotros, p. 18.

41. Putnam, H., La filosofía judía, una guía para la vida. Barcelona, Alpha Decay, 2011, p. 146.

42. Levinas, E., "La presencia de las palabras...", Fuera del sujeto, p. 162.

43. Esta idea evoca la tesis socrática de que la palabra hablada siempre es superior a la escrita, porque a un texto no se le puede interrogar, ni dialogar con él.

44. Levinas, E., "¿Es fundamental la ontología?", Entre nosotros, p. 39. En este aspecto, el planteamiento de Levinas es diametralmente opuesto a lo que defienden Gadamer y otros filósofos de la corriente hermenéutica que consideran que la confrontación con el texto escrito siempre es un momento de alteridad o, por decirlo con Gadamer, de 'fusión de horizontes'.

45. Levinas, E., "¿Es fundamental la ontología?", Entre nosotros, p. 39. 
conversar para llegar a acuerdos, en lugar de recurrir a la violencia o la aniquilación del otro, a la negación de su alteridad para someterla a mis propios deseos o preferencias. A través de la palabra se quiere "evitar la violencia, como si la comunicación y la violencia fueran incompatibles" ${ }^{\prime \prime 4}$, o formas de relación mutuamente excluyentes. El intercambio comunicativo hace aflorar un trasfondo ético que conmina a respetar al otro, a responder a su llamada, a proteger su vida, como luego veremos.

El lenguaje permite el acceso a la alteridad irreductible de lo absolutamente otro, de tal manera que lo lingüístico se inserta y conecta a nivel profundo con la dimensión metafísica: "la relación del Mismo y del Otro -o metafísica- funciona originalmente como discurso, en el que el Mismo, resumido en su ipseidad de 'yo' - de ente particular único y autóctono- sale de sí". ${ }^{47}$ Mediante el lenguaje el yo trasciende sus propios límites y se aproxima a la alteridad radical a la que el Otro le invita a través de la palabra, en tanto que "el Yo únicamente puede salir de sí por la Ilamada del Otro que se produce en la relación cara-a-cara". ${ }^{48}$ De acuerdo con esta lectura, es la alteridad la que interpela al Yo, la que se le presenta y le dirige la palabra, haciéndole salir de su mismidad. A partir de este argumento se entiende la crítica de Ricoeur a Levinas, al que achaca que se apoya "en la iniciativa del otro"49 y que en su pensamiento "el modelo de toda alteridad es el otro" ${ }^{\prime 50}$. Asimismo, Levinas entabla un debate con el modelo de alteridad planteado por Buber, cuya concepción de la relación entre el Yo y el Tú le parece insuficiente porque está guiada por una aproximación al otro como compañero y amigo, se centra en los valores de reciprocidad e interpelación y excluye toda opción distinta a la amistad $^{51}$. Levinas entiende que este enfoque no agota todas las modalidades de relación posible entre el yo y la alteridad, y despliega una propuesta en clave ética donde se ofrece un marco para pensar esas interacciones con más amplitud. Lo vemos a continuación.

46. Domingo Moratalla, A., "Responsabilidad y diálogo en Lévinas. Reflexiones para una ética del cuidado y la solicitud", Alonso Martos. Emmanuel Levinas..., pp. 173-183, p. 178.

47. Levinas, E., Totalidad e infinito, p. 63.

48. Reyes Pedraza, J., "La alteridad en Lévinas", p. 162.

49. Bourgeouis, P., "Ricoeur and Levinas: Solicitude in Reciprocity and Solitude in Existence", Cohen y Marsh (eds.). Ricoeur as another. The ethics of subjectivity. Albany, State University of New York Press, 2002, pp. 109-126, p. 110. Esta crítica no carece de fundamento ya que, como se ha expuesto anteriormente, Levinas pretende situar el núcleo de la subjetividad en una perspectiva descentrada, ubicada en la exterioridad, superando así las propuestas de Husserl.

50. Ricoeur, P., Sí mismo como otro. Madrid, Siglo XXI, 1996, p. 396. Sobre las críticas de Ricoeur a la noción de alteridad desarrollada por Levinas, ver Fernández Guerrero, O., "Sobre la alteridad y la diferencia sexual", Logos. Anales del Seminario de metafísica, 15 (2012), pp. 293-317.

51. Levinas, E., Totalidad e infinito, pp. 91-92. 


\section{El surgimiento de la ética}

Tomando como referencia la relación entre el individuo y la alteridad, Levinas indaga sobre el modo en que lo Mismo puede llegar a captar lo Otro sin cancelar su alteridad en ese movimiento, y llega a la conclusión de que ese tipo de relación únicamente puede fundarse a partir de la ética. Pensar lo infinito o lo extraño no puede reducirse a pensar un objeto, pues entonces estaríamos ya asimilándolo a categorías conceptuales preestablecidas, comprometiendo así su alteridad. Se trata, entonces, de aceptar que lo Otro, la alteridad, se presenta en primera instancia como "rostro", y que esa noción alude a "la anterioridad filosófica del ente sobre el ser, una exterioridad que no recurre al poder ni a la posesión". ${ }^{52}$ El encuentro con la alteridad del Otro particularizado, explicitada y reflejada en el rostro que se sitúa ante mí, viene marcado por unas pautas diferentes en las que no intento someter al otro ni neutralizarlo, sino que adopto ante él una actitud ética. En ese movimiento percibo al Otro como una entidad exterior e irreductible que se sitúa frente a mí y que no puedo controlar ni poseer, y ante la que solamente cabe aceptar su libertad como contrapuesta a mi libertad: el otro "no es mi posible, no depende de mi libertad, sino que es el límite de esta", 53 como dirá Sartre. Ese otro al que me contrapongo "no es expresión de ninguna abstracción, ni siquiera de la 'humanidad'; el otro es quien es" ${ }^{\prime 54}$. No se trata, por tanto, de que el otro sea un signo o una representación de una categoría universal que lo contiene -ya que en ese caso volveríamos a caer de nuevo en la lógica de la Mismidad- sino de que "el hecho de que el rostro mantiene por el discurso una relación conmigo, no lo alinea en el Mismo" ${ }^{\prime 55}$, porque ese rostro conserva su especificidad más allá de las semejanzas que pueda compartir o no conmigo.

"El Otro tiene un rostro y es descrito mediante el rostro; he aquí la posibilidad máxima de expresión y comunicación"; 56 es la relación cara-a-cara la que me pone frente al rostro de otro y permite el surgimiento del intercambio lingüístico, que se enmarca ya desde el comienzo en la esfera de la ética. La comunicabilidad es posible porque "el rostro es una presencia viva, es expresión" esa comunicación facilita que el otro se posicione como alteridad frente a mí y que conserve esa posición: "el hecho de que el rostro mantiene por el discurso una relación conmigo, no lo alinea en el Mismo. Permanece absoluto en la

52. Levinas, E., Totalidad e infinito, p. 75.

53. Sartre, J.-P., El ser y la nada. Madrid, Alianza, 1984, p. 290. Sartre tiene una concepción negativa del encuentro con el otro, que implica un choque de libertades que puede coartar el despliegue del proyecto de vida individual. Levinas tiene una visión más positiva al respecto que la de Sartre.

54. Putnam, H., La filosofía judía, p. 146.

55. Levinas, E., Totalidad e infinito, p. 209.

56. Quesada Talavera, B., "Aproximación al concepto...", p. 403.

57. Levinas, E., Totalidad e infinito, p. 89. 
relación" ${ }^{\prime \prime 58}$. En el diálogo se realiza la interconexión entre dos subjetividades que son, recíprocamente, alteridad particularizada la una con respecto a la otra, y que en este modo de relación preservan esa dimensión de alteridad.

El rostro del otro "es el modo de ser del interlocutor" accesible $-y$ a la vez inasequible e inaprehensible- a través de un rostro que habla, y el lenguaje es "respuesta al ser que le habla en el rostro y que no tolera más que una respuesta personal, es decir, un acto ético" ${ }^{\prime \prime 0}$. Ese acto ético, según Levinas, adquiere también forma lingüística, puesto que la palabra que el otro me dirige debe ser correspondida con otra palabra que yo le dirijo, en respuesta a su palabra primera. "La esencia del discurso es ética"61, y cualquier otra alternativa de interacción con el rostro particularizado que no incluya esa apertura a la comunicabilidad está abocada al fracaso. Solamente se accede al ser por esta vía, porque "la significación de los seres no se manifiesta en la perspectiva de la finalidad, sino en la del lenguaje" ${ }^{\prime \prime 2}$. La única forma lícita de aproximación al otro es abordándolo como fin en sí mismo, como alteridad en sí mismo, y no como instrumento al servicio de mis propios fines -en esta línea la ética de Levinas confluye con la de Kant, aunque la divergencia entre ambos filósofos es evidente, ya que el planteamiento moral kantiano se fundamenta en consideraciones de corte individualista y abstracto mientras que Levinas promueve todo lo contrario; la suya es una ética que no surge del individuo aislado sino que es fruto de la relación de un yo con lo que le rodea, y que además solamente llega a definirse como "yo", como sujeto, en función de esa dimensión relacional-.

Como ya se ha mencionado anteriormente, Levinas establece una disyuntiva entre lenguaje y violencia, entre dialogar y matar, y hace un alegato en favor de la comunicación interpersonal como única opción ética posible. En el rostro particularizado del otro aflora su alteridad, que se aparece ante mis ojos y resuena en mis oídos, que me interpela de una forma directa e ineludible. Ese encuentro puede generar conflicto -tal y como resalta Sartre-, hasta el extremo de que "el otro es el único ente a quien puedo querer matar"63 porque su presencia me incomoda y me genera rechazo, porque su alteridad que se sitúa ante mí se me impone, me habla, me interroga desde su otredad radical. Levinas mantiene que, en esa tesitura, la única respuesta moralmente aceptable es acoger al otro, y añade que esa acogida ha de ser hospitalaria y no totalizadora, "una acogida no apropiativa en mi hogar" ${ }^{\prime \prime 4}$ que renuncia a todo intento de sometimiento del

58. Levinas, E., Totalidad e infinito, p. 209.

59. Samoná, L., Diferencia y alteridad, p. 80.

60. Levinas, E., Totalidad e infinito, p. 232.

61. Levinas, E., Totalidad e infinito, p. 229.

62. Levinas, E., Totalidad e infinito, p. 119.

63. Levinas, E., “¿Es fundamental la ontología?”, Entre nosotros, p. 21.

64. Llewelyn, J., Emmanuel Levinas..., p. 135. La idea de "hogar" es central dentro del pensamiento de Levinas, aunque el desarrollo de esta noción rebasaría los límites de este trabajo. Escuetamente, señalaremos que la forma de acoger al otro que propone este filósofo 
otro, que no se intenta imponer porque acepta de forma solidaria que el otro sea otro, y que se compromete activamente en que lo siga siendo ${ }^{65}$. Ante el rostro del otro debe primar la actitud de acogida, apertura hacia esa alteridad y exterioridad que ese rostro arrastra consigo, pues "el rostro siempre se entrega a una acogida y la acogida acoge solamente un rostro, [...] que debe sustraerse a toda tematización" ${ }^{\prime 66}$. En este eje argumentativo, Levinas apunta que el modelo paradigmático de relación con la alteridad es el encuentro con la feminidad, con "la dulzura del rostro femenino ${ }^{\prime 67}$ al que atribuye una serie de valores relacionados con la hospitalidad, el cuidado, la acogida, etcétera, diametralmente opuestos a la dominación, la imposición, la asimetría, o la agresividad ${ }^{68}$.

Cuando me sitúo ante un rostro que me habla, recurrir a la violencia y matar al otro supone "la supresión éticamente imposible de la alteridad del Otro, la reducción del Otro al mismo" ${ }^{\prime 69}$, algo que para Levinas es radicalmente inaceptable, tanto desde la perspectiva ética como desde un punto de vista ontológico y metafísico, porque el asesinato de un otro concreto no resuelve el conflicto con la alteridad ni la hace desaparecer del mundo. La violencia, por tanto, no solo carece de fundamento ético, sino que también supone un desajuste con respecto a la dimensión ontológica. Ser ético, abrirse a la ética, supone abjurar de la violencia y apostar incondicionalmente por el diálogo.

El instante ético es aquel en el que "sin preparación previa, sin saber, sin poder, sin querer, un hombre se deja trastornar por la trascendencia de otro [...] que exige imperativa e imperiosamente una respuesta de responsabilidad"70. Frente a ese otro que viene hacia mí, que comparece ante mí con toda su trascendencia, no tienen cabida la negación ni la huida sino que la ética conmina a la solicitud, a responder a la llamada que el otro hace. El sujeto de la responsabilidad es aquel que consuma "la salida de sí hacia el Otro: no es para-sí, sino que ha sido

aparece ejemplificada metafóricamente en la actitud de hospitalidad, cuando alguien extraño y ajeno a nuestro hogar es recibido y acogido en él.

65. Sobre esta cuestión resultan muy pertinentes las recientes aportaciones de la ética del cuidado, que complementa los enfoques éticos basados en la aplicación de normas generales con otro tipo de valoraciones relativas al principio de no maleficencia, que atiende a las consecuencias de las decisiones y al posible perjuicio que puedan ocasionar a posteriori, y el principio de cuidado, que atiende a las relaciones personales y a las responsabilidades hacia los demás.

66. Derrida, J., Adiós a E. Lévinas. Palabra de acogida. Madrid, Trotta, 1998, p. 39.

67. Levinas, E., Totalidad e infinito, p. 169.

68. El análisis de este planteamiento excede los límites de este trabajo. Para un estudio más específico sobre este aspecto del pensamiento de Levinas, ver Palacio, M., La mujer y lo femenino en el pensamiento de Emmanuel Levinas. Un debate de género en torno a la alteridad femenina. Córdoba, Universidad Católica de Córdoba, 2008.

69. Llewelyn, J., Emmanuel Levinas..., p. 135.

70. Bensussan, G., "Intransitividad de la ética", Alonso Martos, Emmanuel Lévinas..., pp. 29-40, p. 38. 
constituido como un uno-para-el-otro"71, deja de enrocarse en su identidad para abrirse hacia la alteridad irreductible, y aceptar el reto y la interpelación que esa alteridad le dirige, explícitamente, desde el rostro del otro. El rostro se capta por la mirada, al igual que las demás cosas del mundo, pero además me habla, ya que "el rostro no es objeto del ver que objetiva; es palabra que se deja oír"72, y ahí reside lo específicamente humano en la medida en que "la epifanía del rostro como rostro introduce la humanidad"73.

En Levinas, el plano ético remite a "una esfera previa a la moral, puesto que determina una responsabilidad anterior a la libertad"74. La obligación fundamental que tenemos es la que "nos abre a la necesidad (y especialmente al sufrimiento) de la otra persona" ${ }^{\prime 75}$. Pensar el sufrimiento a través de ese prisma relacional e interhumano implica ir más allá de la consideración de ese sufrimiento desde una perspectiva puramente epistemológica, como contenido de conocimiento similar al que tenemos de otras cosas, y supone ya una respuesta ética que impele a hacerse cargo de ese sufrimiento, a intentar paliarlo, pues "lo interhumano propiamente dicho reside en la no-indiferencia de los unos por los otros [...], en el recurso de los unos al auxilio de otros" ${ }^{\prime \prime 7}$.

La libertad es secundaria con respecto a esta dimensión de solidaridad, de conmiseración, que surge espontáneamente -o debería surgir- de la relación con la alteridad. En todo caso, esa libertad emerge del entramado de las relaciones de sociabilidad y, para este autor, se realiza y despliega, sobre todo, lingüísticamente, en tanto en cuanto "la palabra es [...] una relación entre libertades que no se limitan ni se niegan, sino que se afirman recíprocamente" ${ }^{177}$. "Abordar al Otro es cuestionar mi libertad"78, confrontar mi libertad con la suya y dejar que la alteridad sea libre, querer su libertad -aunque quiera cosas que yo no quieroigual que quiero la mía propia. En definitiva, "ser libre es construir un mundo en el que se pueda ser libre" 79 , esto es, un 'reino de los fines' -en sentido kantiano-

71. Pérez Quintana, A., "La crítica de Levinas...", Alonso Martos. Emmanuel Lévinas..., pp. 69-90, p. 78.

72. Pérez Quintana, A., "La crítica de Levinas...", p. 81.

73. Levinas, E., Totalidad e infinito, p. 226.

74. Samoná, L., Diferencia y alteridad, p. 69.

75. Putnam, H., La filosofía judía..., p. 116.

76. Levinas, E., "El sufrimiento inútil", Entre nosotros, pp. 113-126, p. 125. Las hondas reflexiones de Levinas acerca del sufrimiento y la compasión están muy cercanas a los postulados de Unamuno, que a lo largo de su obra afirma insistentemente que la razón enseña pocas cosas acerca de la condición humana, y que son el amor y la compasión ante las desgracias ajenas lo que más acerca y une a los seres humanos. Para un análisis más pormenorizado de este tema en la obra unamuniana, ver Fernández Guerrero, O., "La antropología de Unamuno: el 'hombre de carne y hueso'", Aragüés y Ezquerra (coords.). De Heidegger al postestructuralismo. Panorama de la ontología y antropología contemporáneas. Zaragoza, Prensas de la Universidad de Zaragoza, 2014, pp. 71-87.

77. Levinas, E., "El yo y la totalidad", Entre nosotros, p. 48.

78. Levinas, E., Totalidad e infinito, p. 307.

79. Levinas, E., Totalidad e infinito, p. 183. 
donde todos y cada uno de los individuos puedan realizar su proyecto individual de libertad.

Avanzando en la exposición, se afirma también que la ética se basa "en la obligación para con el otro y no en una 'semejanza' empírica o metafísica entre yo y el otro" ${ }^{\prime \prime 0}$, porque entonces volveríamos otra vez a caer en la lógica de la Unidad y en el pensamiento de lo Mismo, donde la alteridad sucumbe. Levinas insiste en que, "si solo te sientes obligado ante aquellos por los que sientes simpatía [...], todavía estás atrapado en tu propio ego" ${ }^{\prime 81}$, la ética que se despliega a partir de las fobias y filias particulares es insuficiente, permanece anclada en el narcisismo y en ella subyace, además, un afán de dominación y asimilación que a Levinas le resulta sospechoso. Para desterrar este enfoque se propone una "ética heterónoma" donde el Otro es "maestro que enseña y manda"82, su alteridad me interpela y puedo establecer con ella un intercambio comunicativo que me aproxima parcialmente a esa alteridad, que me permite un cierto contacto en la distancia, radical e insuperable, que separa al yo del otro. Porque "mi proximidad al otro no es una cercanía basada en la semejanza, sino un acercamiento al Otro, que mantiene la distancia y la diferencia de altura desde la que se acerca y me ordena $^{\prime \prime 3}$. Partiendo de estas tesis, se percibe claramente que la relación ética es y ha de ser asimétrica, no puede fundarse en la semejanza porque esto generaría injusticias. De hecho, "uno está obligado a ponerse a disposición del estado de necesidad del otro sin pensar, por ello, que el otro siente la misma obligación" ${ }^{\prime 24}$. La ética de Levinas es altruista, se basa en un yo volcado hacia el otro y ocupado en socorrerle, sin esperar nada a cambio. Esa obligación hacia los demás se plantea de modo radical, evidente, cuando el yo se confronta de forma directa al rostro del otro, pues cuando esto sucede, se pregunta Levinas, "¿no se ha expuesto a la miseria de la desnudez, pero también a la soledad del rostro, y, por tanto, al imperativo categórico de asumir la responsabilidad por esa miseria?"

Se establece una comparación con la relación amorosa, que es recíproca: "es el yo satisfecho en el tú, el que encuentra en otro la justificación de su ser" ${ }^{\prime \prime 6}$. La ética no puede fundarse en ese tipo de correspondencia porque en ese supuesto solo existirían obligaciones morales hacia los seres amados, algo que para Levinas resulta claramente insuficiente: "La ética debe preceder a la reciprocidad; pretender fundar la ética en la reciprocidad supone caer una vez más en el intento de fundarla en la ilusoria 'semejanza' de la otra persona"87. La moral humana

80. Putnam, H., La filosofía judía..., p. 125.

81. Putnam, H., La filosofía judía..., p. 145.

82. Pérez Quintana, A., "La crítica de Levinas...", p. 81.

83. Llewelyn, J., Emmanuel Levinas..., p. 187.

84. Putnam, H., La filosofía judía..., p. 147.

85. Levinas, E., "Fuera del sujeto", Fuera del sujeto, p. 170.

86. Levinas, E., "El yo y la totalidad", Entre nosotros..., pp. 25-51, p. 34.

87. Putnam, H., La filosofía judía..., p. 117. 
se abre "hacia los terceros a quienes se ha abandonado fuera del amor" 88 , y en este sentido "la ley es más importante que la caridad"89, aunque la precede en un sentido ontológico. La capacidad de com-padecer, de responder a la llamada del otro e identificarme con su sufrimiento, forma parte de un movimiento ético que hace que el sí salga de sus confines para encontrarse con la alteridad particularizada en el rostro ajeno, y ese movimiento es previo a cualquier concepción de justicia, que siempre estará basada en consideraciones de carácter más general.

Tal y como señala José María Aguirre a propósito de Levinas, "la vida política es [...] un campo de realización de la ética, pero no el ámbito entero de su concretización" ${ }^{\prime 90}$, pues la ética es mucho más amplia que la política, sus límites son siempre más extensos de lo que cualquier marco jurídico o administrativo puede llegar a establecer. En este sentido, la ética es previa a la justicia, en tanto que "mi libertad y mis derechos [...] se mostrarán precisamente en forma de responsabilidad, en la fraternidad humana. Responsabilidad inagotable, porque no podemos quedar en paz con el otro" ${ }^{\prime 91}$. Los límites y obligaciones autoimpuestos por la ética van mucho más allá de lo que la justicia dicta, y sin embargo es en ese horizonte ético donde la justicia hunde sus raíces y se dota de sentido, pues para Levinas la justicia es ya reconocer al otro como maestro, "es reconocimiento de su privilegio de otro y de su señorío, acceso al otro fuera de la retórica que es engaño, dominio y explotación"92. El primer acto de justicia -y de ética- es no matar, porque el primer privilegio que puede tener un ente concreto es la existencia, y reconocer y respetar ese derecho primordial equivale a dejar que la alteridad del rostro del otro siga existiendo y expresándose, implica renunciar a ejercer violencia sobre él, y conlleva también -en un sentido completamente étiCO- tomar partido a favor de esa existencia, esto es, hacer todo lo humanamente posible para que esa alteridad que se pone de manifiesto en el rostro-sobre todo en el rostro sufriente- no sea destruida.

"La paz no es un proceso de lo negativo, el resultado de un tratado dialéctico entre lo Mismo y lo Otro"93, aunque esa confrontación entre yo y el otro está implícita en el proceso que conduce hacia la paz, entendida como el restablecimiento de la justicia. Para que ese restablecimiento se produzca, primero es necesario identificar la injusticia, y en ese paso resulta imprescindible el encuentro con la alteridad, con el rostro del otro, pues "para que yo conozca mi injusticia [...] se precisa que alguien me pida cuentas" ${ }^{\prime \prime 4}$. Así, de nuevo, es la interpelación del otro, lanzada a través de la palabra, la que me hace cuestionar los efectos

88. Levinas, E., "El yo y la totalidad", Entre nosotros..., pp. 25-51, p. 36.

89. Levinas, E., "El yo y la totalidad", Entre nosotros..., p. 36.

90. Aguirre, J. M., "De la Ética a la Justicia", Bajo palabra. Revista de filosofía, Il época 8 (2013), pp. 125-138, p. 138.

91. Levinas, E., "Los derechos humanos y los derechos del otro", Fuera del sujeto, p. 148.

92. Levinas, E., Totalidad e infinito, p. 95.

93. Derrida, J., Adiós a Levinas, p. 119.

94. Levinas, E., "El yo y la totalidad", Entre nosotros..., p. 44. 
de mis acciones, la que me empuja a examinar sus consecuencias desde una perspectiva que trasciende los límites de la subjetividad y que me coloca en la exterioridad, esa exterioridad ajena a mí y que, sin embargo, padece mis actos.

En síntesis, para Levinas la única relación posible y adecuada con el otro es de carácter ético, está mediada por el lenguaje, y se basa en tres ejes centrales: el absoluto respeto por la alteridad del otro, la compasión ante su sufrimiento, y la acérrima defensa de su libertad.

\section{Consideraciones finales: la confluencia de todas las dimensiones en el plano ético}

Partiendo de las ideas de totalidad e infinito, Levinas pone en tela de juicio toda la tradición filosófica occidental basada en la idea de sujeto y centrada en descifrar las claves de la identidad de ese sujeto, frente al que todo lo demás queda relegado a un segundo plano. Precisamente, es el deseo de invertir esta perspectiva el que le lleva a desplegar un pensamiento de la alteridad que ilumina esa zona oscurecida del plano, esa dimensión del mundo que es no-yo, diferencia, exterioridad, lo Otro en su máxima amplitud y radicalidad. Las ontologías del yo se le antojan empobrecedoras, y las sustituye Levinas por una ontología de la alteridad que sitúa todo lo que no es yo en el núcleo de la reflexión filosófica, y en el centro de la "mismísima" metafísica -mismísima en sentido figurado, claro está, porque la metafísica elude toda pretensión de describirla, 'identificarla', reducirla a sus enunciados simples y encorsetarla en la lógica de lo Uno, de lo Mismo, de lo semejante-. Yendo más allá de lo mismo, "la unicidad irreductible del otro define un espacio cognoscitivo que sobrepasa la ontología"95, que cuestiona los límites de la ontología tal y como ha sido definida por el discurso filosófico occidental. Y es precisamente la idea de alteridad la que permite Ilevar a cabo ese desplazamiento conceptual, por cuanto ensancha el horizonte desde el que se intenta comprender $-\mathrm{O}$, mejor dicho, atisbar- el Ser.

En esa nueva mirada surge la dimensión de lo infinito, que no se conoce por captación directa sino por aproximación, por intuición, por otro tipo de capacidades que nada tienen que ver con las dimensiones cognitivas tradicionalmente asociadas a la racionalidad cartesiana, sino que se asocian más al sentimiento de la presencia de algo trascendente, inabarcable, inefable. Una de las manifestaciones de esa infinitud es la idea de Dios, pero no es la única, ya que la infinitud se expresa también a través de otros encuentros, de otras vivencias. Una de ellas, a la que Levinas concede especial importancia, es el encuentro con el rostro del otro, que para este filósofo tiene tintes metafísicos. De hecho, es la confrontación con el otro, la situación cara-a-cara frente a él,

95. Samoná, L., Diferencia y alteridad, p. 61. 
la que inaugura una apertura a la alteridad. La posibilidad de relación no dominante con la alteridad se materializa cuando se entabla un diálogo con ese otro, cuando el sujeto responde a la palabra que el otro profiere y esa respuesta toma también forma de palabra -porque cuando la respuesta a la llamada del otro es la violencia, se cancela toda posibilidad de relacionarse con la alteridad dejándola ser, dejándola desplegarse-. Así, la relación con la alteridad está condicionada por el plano ético, que marca a priori unas pautas, unas reglas inquebrantables por las que ese intercambio se ha de guiar. El encuentro con la alteridad representada por el otro no se reduce, no ha de reducirse a captarlo como mero objeto, o como cosa entre otras cosas: "el encuentro con el Otro ha de ser buscado recorriendo un camino ajeno a la teoría; si existe una verdadera alteridad, solo cabe mantener con ella una relación diferente de la relación sujeto/objeto mediante el conocimiento"96. El otro no es un objeto ante el que deba adoptarse la posición de sujeto, no es algo que se pueda poseer o dominar o controlar, sino que es, ante todo y sobre todo, otro que merece mi respeto, y cuya libertad debo defender en igual medida que defiendo mi propia libertad. Con Levinas, "la ética aparece como filosofía primera para mantener despierto y vigilante el sentido de una vida moral pensada en términos de responsabilidad" ${ }^{\prime 97}$. Los contenidos de la moral no surgen del plano autónomo sino que arraigan en la heteronomía; es el otro el que me interpela, me habla, y ese movimiento me hace ir hacia él, acercarme e interactuar con él, pero sin anular su especificidad ni cancelar su alteridad.

El plano ético es el punto de clausura de todos los demás planos, de todas las demás dimensiones de la alteridad. El ego se encuentra frente al alter, comprometido con él, condenado a entenderse con él porque la alteridad es imposible de cancelar, incluso al nivel ontológico. La apertura a la alteridad se traduce, en parte, en un deseo religioso que anhela la conexión con la totalidad, la fusión con lo trascendente, pero que no se agota en ese deseo sino que se manifiesta también en el encuentro con la alteridad del otro humano. El rostro del otro, en el planteamiento de Levinas, es siempre una epifanía de la alteridad, ante la que solamente es aceptable adoptar una postura ética que lleva al individuo a desplegar sus capacidades comunicativas, a hablar y dejarse hablar, a escuchar la palabra, la llamada que el otro le lanza, y a responder con su compromiso a esa Ilamada. Nada de violencia, nada de silencio. Solamente la llamada de quien sufre, y la respuesta solidaria de quien se conmueve ante su dolor.

96. Pérez Quintana, A., "La crítica de Levinas...", Alonso Martos. Emmanuel Levinas..., pp. 69-90, p. 77.

97. Domingo Moratalla, A., "Responsabilidad y diálogo...", Alonso Martos. Emmanuel Levinas, pp. 173-174. 


\section{Bibliografía}

AGUIRRE, J. M., "De la Ética a la Justicia”, Bajo palabra. Revista de filosofía, II época 8 (2013), pp. 125-138.

ALONSO MARTOS, A., Emmanuel Lévinas. La filosofía como ética. Valencia, Universitat de València, 2008.

BOURGEOUIS, P., "Ricoeur and Levinas: Solicitude in Reciprocity and Solitude in Existence", Cohen y Marsh (eds.). Ricoeur as another. The ethics of subjectivity. Albany, State University of New York Press, 2002, pp. 109-126.

DERRIDA, J., Adiós a E. Lévinas. Palabra de acogida. Madrid, Trotta, 1998.

FERNÁNDEZ GUERRERO, O., "Sobre la alteridad y la diferencia sexual", Logos. Anales del Seminario de metafísica, 15 (2012), pp. 293-317.

FERNÁNDEZ GUERRERO, O., "La antropología de Unamuno: el 'hombre de carne y hueso'", Aragüés y Ezquerra (coords.). De Heidegger al postestructuralismo. Panorama de la ontología y antropología contemporáneas. Zaragoza, Prensas de la Universidad de Zaragoza, 2014, pp. 71-87.

LEVINAS, E., Fuera del sujeto. Madrid, Caparrós, 1997.

LEVINAS, E., Totalidad e infinito. Ensayo sobre la exterioridad. Salamanca, Sígueme, 1999.

LEVINAS, E., Entre nosotros. Ensayos para pensar en otro. Valencia, Pre-textos, 2001.

LLEWELYN, J., Emmanuel Levinas. La genealogía de la ética. Madrid, Encuentro, 1999.

PALACIO, M., La mujer y lo femenino en el pensamiento de Emmanuel Levinas. Un debate de género en torno a la alteridad femenina. Córdoba, Universidad Católica de Córdoba, 2008.

PUTNAM, H., La filosofía judía, una guía para la vida. Barcelona, Alpha Decay, 2011.

QUESADA TALAVERA, B., "Aproximación al concepto de 'alteridad' en Lévinas. Propedéutica de una nueva ética como filosofía primera". Investigaciones fenomenológicas, 3 (2011), pp. 393-405.

REYES PEDRAZA, J., "La alteridad en Emmanuel Levinas", Martínez Contreras y Ponce de León (coords.). El saber filosófico. Sociedad y ciencia. México, Siglo XXI, 2007, pp. 159-167.

RICOEUR, P., Sí mismo como otro. Madrid, Siglo XXI, 1996.

SAMONÁ, L., Diferencia y alteridad. Después del estructuralismo: Derrida y Levinas. Madrid, Akal, 2005.

SARTRE, J.-P., El ser y la nada. Madrid, Alianza, 1984. 